\title{
The acoustic analysis of voice parameters about the vowels and consonants of Lhasa Tibetan
}

\author{
ZeguoLiu/s per $1^{\text {st }}$ \\ Science and Technology Department, \\ Tibet University for Nationalities \\ Xianyang, China \\ ajycyt@126.com \\ JinyongAi per $3^{\text {nd }}$ \\ Tibet University for Nationalities \\ Xianyang, China \\ ajy0529@126.com
}

\author{
XiaoyingChen ${ }^{1} / \mathrm{s}$ per $2^{\text {nd }}$ \\ Information Engineering Institute, \\ Tibet University for Nationalities \\ Xianyang, China \\ 283049683@qq.com
}

\begin{abstract}
- this paper's study focuses on the vowels and consonants of Lhasa Tibetan, with the basic voice parameters, it is found that there is high relevance among the fundamental frequency(F0),open quotient (OQ) and speed quotient (SQ)of the 8 monophthongs which are in the V,CV and VC 3 types. Among the 3 types, the consonant ending has great influence onvoice parameters than the prefix consonants. The influences of different vowelsin the 3types on the voice parameters are the same. Meanwhile, the voice parameters of the consonants are different as the consonants 'different phonation conditions and different locations that are in syllables, in addition, the voice parameters of the consonants are also different with different vowels.
\end{abstract}

Keywords-EEG;Lhasa dialect; vowels;consonants;

\section{INTRODUCTION}

The study of voice parameters is one of the most important parts of the acoustics study of speech; it is also the foundational theory research of language. During the phonetics study, the voal cord vibrations' characters can be known, and so can some of the physiological activities around the vocal cord with the EEG signals [1]. Hence, a good study of the characters of the voice parameters can contribute the study the speech signals' change rules.

For the acoustic analysis of voice parameters, the professor Jiangpin Kong of Peking University pointed out that: with the EEG signals of speech, we can make an acoustics pronunciation atlas. He also pointed out that: with the acoustics pronunciation atlas which comes from the voice parameters, we can describe the characters of different phonation types [2][3].

About the voice study for languages, we have done much work on Chinese speech's phonation types. Tibetan is one of the most important national languages. It is also such a kind language that has a long history and is used in widely areas and among large population. With the modern phonetics study methods, ithasvery important scientific and practical significance in linguistics, engineering phonetics and sociology to do some research of Tibetan, put up a voice parameter's database[4][5]. In our country, the main three dialects of Tibetan are Lhasa dialect, Anduo dialect, and Kang dialect, among of them, pronunciation is the most difference. This paper focuses on Lhasa dialect, aims to find the relevance in the vowels' voice parameters and the ${ }^{1}$ different consonants' affections on the different vowels, which can provides the previous foundational research for establishing the phonation types of Lhasa dialect.

\section{EXPERIMENTAL SCHEME}

\section{A. Collecting EEG signals}

All the samples recording are the single syllables of Lhasa dialect. The speaker comes from Lhasa, and has no voice medical history. The EEG signals have been collected in a professional recording studio, and which contains speech and voice. The sample frequency is $40 \mathrm{kHz}$.

The equipment in this study is Electroglottograph Model. It always can be used in the study of speech voice and pathological linguistics. The working principles of the equipment like that: first, there is a pair of sensors to be put thyroid cartilage quite close. When there is a speech product, small high frequency signals can be obtained from one sensor and be transported to the other sensor. There will be the minimal impedance when there is a sufficient glottis closure. There will be the maximal impedance when there is an insufficient glottis closure. Based on the glottal impedance signals, the point- in-times of the glottis' open and closure could be obtained; meanwhile, based on all of the voice parameters, the study could be further.

\section{B. Extracting parameters}

After marking the recordings, the voice parameters can be getting from the Multi-Speech 3700 soft. The voice parameters concluded the fundamental frequency (F0), open quotient (OQ) and speed quotient (SQ). All of the parameters had been stored as .txt. For the combinations of vowel and

${ }^{1}$ Co-corresponding author: XiaoyingChen 
consonant, the voice parameters can be gotten from by the programs which are written with Matlab soft.

Figure 1. The definition of fundamental frequency(F0), open quotient (OQ) and speed quotient (SQ) in EEG signals ${ }^{[6]}$

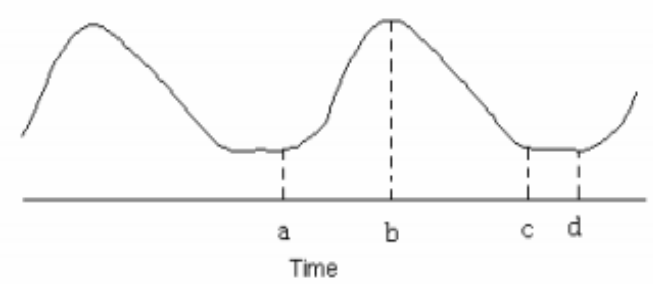

For the speech signals, the fundamental frequency is the reciprocal of the cycle. Open quotient is the ratio between the point- in-time of glottis' open and cycle. [7] Speed quotient is the ratio between all of the time of glottis' open and all of the time of glottis' closure.

From the above Figure1, it can be seen the basic form of EEG signals. Usually, the forms of the signal waves are leaning to the left. In the figure, $a b$ is the point- in-time of glottis' closure; bd is the point- in-time of glottis' open; bc is all of the time of glottis' open; cd is all of the time of glottis' closure. The fundamental frequency (F0), open quotient (OQ) and speed quotient (SQ) can be definite with the formulas below:

- Fundamental frequency $(\mathrm{F} 0)=1 /$ cycle $(\mathrm{ad})$

- Open quotient $(\mathrm{OQ})=$ the point- in-time of glottis' open (cd) / cycle (ad) $\times 100 \%$

- Speed quotient (SQ) = all of the time of glottis' open ( $b c$ ) / all of the time of glottis' closure ( $a b)$ $\times 100 \%$

\section{Analysis}

There are 8single vowels in Lhasa dialect, which possess different meanings and grammar functions [8]. During the experimental analysis, we extract the 8 single vowels' voice parameters. For the consonant, as voiceless consonant cannot cause the voal cord vibration, we extracting voiced consonants' voice parameters. According the ways of pronunciation, the voiceless consonants can be divided with nasal consonant $(/ \mathrm{m} /, / \mathrm{n} /, / \mathrm{n} /$, and $/ \mathrm{y} /)$, lateral consonant $(/ \mathrm{l} /)$, trill consonant $(/ \mathrm{r} /)$, and semi-vowel $(/ \mathrm{w} /, / \mathrm{j} /)$.

\section{FUNDAMENTAL FREQUENCY(F0)}

The fundamental frequency (F0) is the basic frequency of the vocal cord vibration, which indicates the times of vibration in a second, fundamental frequency is also one of the common indexes for the acoustic measurement.

\section{A. The vowel's frequency}

All of the vowels' frequencies in different types can be seen from the table1.
Table 1. The vowels' frequence

\begin{tabular}{|c|c|c|c|}
\hline $\mathrm{F} 0(\mathrm{~Hz})$ & $\mathrm{V}$ & $\mathrm{C}+\mathrm{V}$ & $\mathrm{V}+\mathrm{C}$ \\
\hline $\mathrm{a}$ & 129 & 131.6 & 133.9 \\
\hline$\varepsilon$ & 128.3 & 135.9 & 139.9 \\
\hline $\mathrm{e}$ & 137.7 & 147.8 & 142.9 \\
\hline $\mathrm{i}$ & 137.1 & 137.9 & 145.8 \\
\hline $\mathrm{o}$ & 131.8 & 140.9 & 132.7 \\
\hline$\varnothing$ & 134.5 & 143.3 & 147.5 \\
\hline $\mathrm{u}$ & 139.2 & 148.5 & 140 \\
\hline $\mathrm{y}$ & 140 & 153.4 & 151.3 \\
\hline
\end{tabular}

From the above table it can be seen:

- The different types of vowels' frequency is $\mathrm{VC}>\mathrm{CV}>\mathrm{V}$, but the different vowels' ranges are not the same.

- From $\mathrm{V}$ to $\mathrm{CV}$, and from $\mathrm{V}$ to $\mathrm{VC}$, the ranges of the 8 different single vowels all are $0.8 \mathrm{~Hz}-13 \mathrm{~Hz}$.

\section{B. The consonants' frequency}

All of the consonants' frequencies in different types can be seen from the table2.

Table 2. The consonants' frequence

\begin{tabular}{|c|c|c|c|c|c|}
\hline F0 (Hz) & N-VC & L-CV & T-CV & T-VC & S-CV \\
\hline $\mathrm{a}$ & 137.87 & 147.18 & 113.94 & 109.36 & 136.85 \\
\hline $\mathrm{e}$ & 129.9 & 150.8 & 155.1 & 132.2 & 115.9 \\
\hline$\varepsilon$ & 138.42 & 125.31 & 142.74 & $\backslash$ & 117.3 \\
\hline $\mathrm{i}$ & 127.75 & 145.4 & 121.93 & $\backslash$ & 170.1 \\
\hline $\mathrm{o}$ & 140.96 & 163.1 & 137.58 & 115.4 & 133.8 \\
\hline$\varnothing$ & 141.5 & 146.74 & 138.5 & $\backslash$ & 151.7 \\
\hline $\mathrm{u}$ & 131.7 & 153.63 & 120.96 & 119.82 & 172.9 \\
\hline $\mathrm{y}$ & 150.36 & 149.77 & 127.14 & $\backslash$ & 160.5 \\
\hline
\end{tabular}

(Notes: in the above table, letter $\mathrm{N}$ indicates nasal consonant, letter $\mathrm{L}$ indicates lateral consonant, letter $\mathrm{T}$ indicates trill consonant, letter $\mathrm{S}$ indicates semi-vowel.)

From the above table it can be seen:

- When it is a rounded vowel and the tongue's position of its pronunciation is high, the frequency of nasal consonant is lager, which indicates that the frequency of the nasal consonant has some relationship with the physiological properties of the vowels.

- The values of frequency of lateral consonant are different, when they combined with different vowels, which indicate that the frequency of the lateral consonant has been affected by the vowels.

- If the vowels are same, the frequencies of trill consonant in the $\mathrm{CV}$ style is larger than in the $\mathrm{VC}$ style, which indicates that the frequency of the trill consonant has been affected by its position.

- The voice parameters of semi-vowel are similar with the voice parameters of vowel, which indicates that there are many similarities not only in the acoustic 
features but also the voice parameters between semivowel and vowel.

\section{OPEN QUOTIENT (OQ)}

The open quotient (OQ) is the open phrase's proportion of the total cycle when the voal cord is vibrating. The opening quotient $(\mathrm{OQ})$ indicates the time's proportion of the total time in voice production when the glottis is opening. The open quotient (OQ) is also one of the common indexes for the acoustic measurement.

A. The vowel's open quotient

Table 3. The vowels' open quotients

\begin{tabular}{|c|c|c|c|}
\hline $0 Q(\%)$ & $\mathrm{V}$ & $\mathrm{C}+\mathrm{V}$ & $\mathrm{V}+\mathrm{C}$ \\
\hline $\mathrm{a}$ & 65.7 & 61.9 & 61.9 \\
\hline$\varepsilon$ & 63.4 & 63 & 61.1 \\
\hline $\mathrm{e}$ & 63.2 & 61.3 & 58.7 \\
\hline $\mathrm{i}$ & 64.4 & 65.1 & 62.9 \\
\hline $\mathrm{o}$ & 61.9 & 60.8 & 60.6 \\
\hline$\varnothing$ & 64 & 63.9 & 58.5 \\
\hline $\mathrm{u}$ & 67.1 & 68.8 & 64.8 \\
\hline $\mathrm{y}$ & 67.3 & 62.1 & 64.8 \\
\hline
\end{tabular}

From the above table it can be seen:

- The variation tendencies of the open quotient are same for the 8 single vowels, and in the 3 types, it likes $\mathrm{VC}>\mathrm{CV}>\mathrm{V}$, but the ranges for different vowels are different.

- From $\mathrm{V}$ to $\mathrm{C}+\mathrm{V}$, the range of the 8 different single vowels is $1.3 \%-5.5 \%$, and the order is $\varnothing>\mathrm{e}>\mathrm{a}>\mathrm{y}>\varepsilon=\mathrm{u}>\mathrm{i}>\mathrm{O}$. From $\mathrm{V}$ to $\mathrm{VC}$, the ranges of the 8 different single vowels is irregular, but all of the values are less than the values in $\mathrm{V}$ to $\mathrm{VC}$.

\section{B. The consonants' open quotient}

All of the consonants' open quotient in different types can be seen from the table 4 .

Table4. The consonants' open quotient

\begin{tabular}{|c|c|c|c|c|c|}
\hline OQ (\%) & $\mathrm{N}-\mathrm{VC}$ & $\mathrm{L}-\mathrm{CV}$ & $\mathrm{T}-\mathrm{CV}$ & $\mathrm{T}-\mathrm{VC}$ & $\mathrm{S}-\mathrm{CV}$ \\
\hline $\mathrm{a}$ & 60.2 & 60.1 & 57.2 & 55.4 & 52.2 \\
\hline $\mathrm{e}$ & 59.8 & 57.8 & 55.9 & 57.2 & 56.3 \\
\hline$\varepsilon$ & 59.4 & 58.3 & 58.7 & 59.4 & $\backslash$ \\
\hline $\mathrm{i}$ & 61.5 & 61.2 & 60.3 & 65.6 & $\backslash$ \\
\hline o & 60.4 & 59.6 & 56.1 & 60.8 & 57.5 \\
\hline$\varnothing$ & 59.8 & 59.3 & 56.5 & 58.7 & $\backslash$ \\
\hline $\mathrm{u}$ & 64.2 & 62.7 & 58.3 & 70.3 & 58.1 \\
\hline $\mathrm{y}$ & 60.3 & 58.4 & 59.8 & 63.5 & $\backslash$ \\
\hline
\end{tabular}

From the above table it can be seen:

- All the values of open quotient of nasal consonant are lager in CV style compared with the VC style, which indicates that the open quotient of the nasal consonant as been affected by its position.
- The values of open quotient of lateral consonant are different, when they combined with different vowels, which indicate that the frequency of the lateral consonant has been affected by the physiological properties of vowels.

- If the vowels are same, values of open quotient of trill consonant in the CV style is larger than in the VC style, which indicates that the values of open quotient of the trill consonant has been affected by its position.

- The voice parameters of semi-vowel are similar with the voice parameters of vowel, which indicates that there are many similarities not only in the acoustic features but also the voice parameters between semivowel and vowel.

\section{SPEED QUOTIENT (SQ)}

The speed quotient $(\mathrm{OQ})$ is the ratio between the value of opening phrase and the value of closing phrase, which is also the ratio between the time of opening phrase and the time of closing phrase, and indicates the moving process of the voice production.

A. The vowel's speed quotient

Table 5. The vowels' speed quotients

\begin{tabular}{|c|c|c|c|}
\hline SQ (\%) & V & C+V & V+C \\
\hline $\mathrm{a}$ & 299.6 & 296.4 & 345.5 \\
\hline$\varepsilon$ & 313 & 309.8 & 316.8 \\
\hline e & 300.4 & 283.8 & 332.8 \\
\hline i & 248.1 & 271.1 & 290.3 \\
\hline o & 337 & 329.3 & 360 \\
\hline$\varnothing$ & 322.2 & 261.1 & 328.7 \\
\hline u & 229.8 & 208.7 & 289.3 \\
\hline y & 243.2 & 202.3 & 204.7 \\
\hline
\end{tabular}

From the above table it can be seen:

- The range of the speed quotient is $202.3 \%-360.0 \%$ for the 3 styles, and the variation tendencies for the 8 single vowels are disordered, which indicate that the speed quotient may have been affected much by other factors.

- All the values of speed quotient of vowel are lager in CV style compared with the VC style, which indicates that the speed quotient of vowels has been affected much by the consonant's ending position.

\section{B. The consonants' speed quotient}

All of the consonants' speed quotient in different types can be seen from the table6. 
Table 6. The consonants' speed quotient

\begin{tabular}{|c|c|c|c|c|c|}
\hline SQ (\%) & N-VC & L-CV & T-CV & T-VC & S-CV \\
\hline a & 265.2 & 258.1 & 259.1 & 244.5 & 226.5 \\
\hline e & 330.3 & 258.7 & 203.1 & 296.9 & 245.2 \\
\hline$\varepsilon$ & 263.9 & 260.2 & 230.5 & 268.7 & $\backslash$ \\
\hline i & 261.8 & 229.1 & 250.1 & 216.9 & $\backslash$ \\
\hline o & 253.5 & 245.1 & 228.3 & 201.8 & 231 \\
\hline$\varnothing$ & 243.7 & 247.5 & 218 & 223.1 & $\backslash$ \\
\hline u & 201.4 & 236.1 & 176.6 & 212.9 & 242.6 \\
\hline y & 194.3 & 193.5 & 186.7 & 254.3 & $\backslash$ \\
\hline
\end{tabular}

From the above table it can be seen:

- All the values of speed quotient of nasal consonant are lager in CV style compared with the VC style, which indicates that, the open quotient of the nasal consonant as been affected by its position.

- The values of speed quotient of lateral consonant are different, when they combined with different vowels, which indicate that the speed quotient of the lateral consonant has been affected by the physiological properties of vowels.

- If the vowels are same, values of speed quotient of trill consonant in the $\mathrm{CV}$ style is larger than in the VC style, which indicates that the values of open quotient of the trill consonant has been affected by its position.

- The voice parameters of semi-vowel are similar with the voice parameters of vowel, which indicates that there are many similarities not only in the acoustic features but also the voice parameters between semivowel and vowel.

- In the CV style, the order for the consonants "value is nasal consonant>trill consonant>lateral consonant; In the $\mathrm{VC}$ style, the order for the consonants 'value is trill consonant>nasal consonant>lateral consonant; both can indicate that the value of speed quotient for the trill consonant is always larger than others.

\section{RESULTS}

With the above table $1-6$, it is can be found that the changing of voice parameters for the three types is different for the vowels and consonants:

A. With the value of frequency's increasing, the value of speed quotient is reducing, which indicates that there is an inverse relationship beteween the the value of frequency and the value of speed quotient.

B. There is a diversityin all of the voice paremeters for the vowels. The voice paremeters are comparetablely regular in V style, but it is indistinctive in VC style. There is a disorder of the voice paremeters in CV style, which indicates that the voice paremeters may have been affected much by other factors.
C. For in consonants, the value of frequency of nasal consonant always is larger than other voiceless consonants'; the value of open quotient of nasal consonant always is larger than other voiceless consonants'; both of them may caused by the way of voice production and the position of the voice production. the value of speed quotient of trillconsonant is larger.

\section{COMMENTS}

In this paper, we have taken some studies on the vowels and consonants of Lhasa Tibetan. Based on the study, the data of frequency(F0), open quotient (OQ) and speed quotient can be obtained, and some rules about the voal cord vibration, which can support a certain reference to the future voice production studies. All of the contents in this paper are preliminary studies; the internal relationship between voice characters and the speech signals has not been referred in this paper. It is expected that there more studies can be taken on the acoustical features of the voice parameters for phonetics, which can cause the voice parameters be understood clearly, and widen the engineering language studies of Tibetan.

\section{ACKNOWLEDGMENT}

The success of this project was subsidized by the projects of the State Ethnic Affairs Commission (12XZZ003), the open project of The Key Lab of China's National Linguistic Information Technology (2012KF013) and the school project (11myZ05)

\section{REFERENCES}

[1] Jiangpin Kong.On Language Phonation.[M].Beijing:Central University for Nationalities Press,2001,1 3

[2] ZongjiWu, Maocan Lin. Summary of Experimental Phonetics.[M].Beijing: Higher Education Press, 1989,34 44

[3] Jinfang Li.The Study and Theory Contribution of Tibatan Phonetcis.[J].Journal of Tibet Nationalities Institute,1995, 01,66 69

[4] Jiangpin Kong. The Study and Relervant Fields of Speech Production.[C].Beijing:China Information Processing Society of China,2001,1 8

[5] Aitang Qu, Xiaojing Jin.The Study Methords of Tetatan dialects.[J].Journal of Southwest University For Nationalities, 1981,03:76 84.

[6] Jiangpin Kong. T Template Manual of AnnualReport of Phonetics Lab.[J]. The Research Reports of Speech Rhythm,2008,1 13

[7] AnanthapadmanabhaT.V. Acoustic analysis of voice source dynamics. Speech Transmission Laboratory - Quarterly Progress and Status Report, Roya Institute of Technology, Stockholm. 1984. 2 3, 1 24.

[8] KerangTan, Jiangpin Kong.TheLongth of the Vowels and the Relation ship bewteen It and Tones of Tebatan.[J].Minority Languages of China,1991,02:12 21. 